\title{
LO UNO Y LO MÚLTIPLE EN LA NARRATIVA DE ANTONIO PRIETO
}

The One and the Multiple in the Narrative of Antonio Prieto

\author{
Álvaro Alonso \\ Universidad Complutense \\ alvaroalonso@,filol.ucm.es \\ ORCID ID: 0000-0001-6008-059X
}

Recibido: 10-10-2020 / Aceptado: 09-01-2021 DOI: https://doi.org/10.51743/cilh.vi46.181

RESUMEN El concepto de fusión mitica es fundamental en la narrativa y crítica de Antonio Prieto. En este trabajo intento mostrar que esa idea obedece a una visión del mundo que privilegia el todo sobre las partes y las especies sobre los individuos (y en este sentido puede calificarse como platónica). Antes de forjar el concepto de fusión mítica, esa noción de la realidad se refleja ya en las primeras novelas del autor, las de los años 50 y 60 , que anticipan así su producción de madurez, correspondiente a los años finales del siglo XX y primeros del XXI.

PALABRAS Clave: Antonio Prieto; mito; platonismo; novela española; novela desde 1950.

ABSTRACT The concept of fusión mitica is a relevant one in Antonio Prieto's narrative and critical work. In this article, I try to show that this idea stems from a vision of the world that gives preference to the whole over the parts and the species over the individuals (a vision that can be described as platonic). Before forging the concept of mythical fusion, this notion of reality is already reflected in the author's first novels, written in the 1950s and 1960s, thus anticipating his mature production, corresponding to the final years of the $20^{\text {th }}$ century and first years of the $21^{\text {st }}$ century.

KEY WORDS: Antonio Prieto; Myth; Platonism; Spanish Novel; Novel after 1950. 


\title{
LO UNO Y LO MÚLTIPLE \\ EN LA NARRATIVA DE ANTONIO PRIETO
}

\author{
ÁlVAro AlONSO \\ Universidad Complutense de Madrid
}

EN LA PRODUCCIÓN novelística de Antonio Prieto el problema de lo uno y de lo múltiple ocupa un lugar de excepcional importancia. La formulación más intensa de esa cuestión, y la más cercana a los planteamientos platónicos, se da en la obra del novelista a partir de la noción de «fusión mítica», sobra la cual volveré más adelante. No obstante, en las páginas que siguen intentaré mostrar que ese concepto está ya esbozado en la más temprana producción del autor. Con objeto de acotar el terreno, abordaré el tema fundamental, aunque no exclusivamente, desde una perspectiva lingüística, lo que equivale a detenerse en la reflexión sobre los nombres propios que proponen estos textos.

La cuestión aparece ya en la primera novela de Prieto, y lo hace al menos de dos maneras diferentes:

a) El personaje se funde con un todo en el que pierde su individualidad. El protagonista, Luigi, se ha adentrado en la selva con el propósito de reencontrar a la amada, María Elena y, perdido entre la vegetación, razona:

Todo aquí se llama vida, exuberante vida. Únicamente el hombre diferencia a las partículas y las llama rama, jabé, boa o liana. Pero sus nombres son 
vida [...] No existe la rama o el jabé o la boa o la liana; no, existe la vida. Y yo, mi ser Luigi, soy vida, siempre seré vida en la selva, porque nada puede morir aquí, porque no existe la muerte [Prieto, 1955: 216].

De manera que la multiplicidad de individuos, e incluso de especies, es un espejismo: una segmentación que la mente y el lenguaje humano imponen arbitrariamente a una realidad que, en sí misma, es única e indivisible. El yo individual, el de Luigi en este caso, participa también de esa naturaleza ilusoria ya que, en realidad, es vida, parte de un todo a través del cual obtiene la salvación. En el pensamiento de Prieto, la disolución de la individualidad tiende a verse como un alivio porque el individuo es mortal, pero el todo no está afectado por la muerte. Unos años después, resumiendo esta escena de su primera obra, el novelista hará decir a uno de sus personajes: «He comprendido cómo en plena selva virgen aquel italiano se defendía instintivamente de la muerte, pensando que no iba a morir, sino a transformarse en vida de la selva» [Prieto, 1961: 129].

b) El individuo se identifica con otro, o con otros, que caen bajo el mismo concepto general. Así, uno de los narradores de la historia, Juan, odia a su compañero de viaje, Gad, que se burla frecuentemente de su poca inteligencia:

Sí, odiaba a Gad desde que tuve nueve años y ahora lo sabía. Se trataba del mismo hombre, de primero que me llamó tonto y que entonces fue un maestro de escuela de Lavapiés. [Prieto, 1955: 107]

En realidad, el personaje no odia a Gad desde los nueve años, por la sencilla razón de que entonces no lo conocía. Pero su verdugo de ahora se identifica con el de la infancia («se trataba del mismo hombre»), hasta el punto de que este puede ser bautizado con el nombre de aquel. De forma todavía vacilante, estas identificaciones adelantan la fusión mítica y, al igual que esta, suponen una abolición del tiempo: en la realidad más profunda, Juan y Gad se conocen desde siempre, desde mucho antes de emprender juntos el viaje por la selva. 
Siempre en Tres pisadas de hombre, Luigi ayuda a una muchacha indígena que está dando a luz. Una vez terminado el parto, le da de beber:

Acerco agua a sus labios [...] Y el rostro de María Elena se confunde con el de ella, como si ambas, en este instante, fueran madres [...] Tuhaí es completamente distinta a María Elena y, sin embargo, yo la he visto en ella [Prieto, 1955: 107].

De nuevo dos personajes se confunden hasta casi perder su individualidad: «el rostro de María Elena se confunde con el rostro de ella».

Planteamientos semejantes vuelven a aparecer en las siguientes novelas de Prieto, empezando por Buenas noches, Argüelles, de 1956. Aquí se encuentran de nuevo los dos mecanismos de disolución de la individualidad que he señalado en Tres pisadas de hombre:

a) El narrador se sitúa en el punto de vista del todo, lo que le permite vencer a la muerte:

Un hijo como Trompo le estaría gritando constantemente que la muerte no detiene nada, le diría minuto a minuto que carece de importancia morir, porque la vida sigue estando ahí sobre la tierra [...] [Prieto, 1956: 138].

Naturalmente, para afirmar que la muerte no detiene nada es preciso obviar como irrelevantes las muertes individuales y centrar la atención en el fluir de la totalidad, o de «la vida», como prefiere llamarla el novelista.

b) Sin llegar a la identificación que proponen casos como el de Gad y el maestro de escuela, son frecuentísimos los personajes que actúan (o sienten o son) igual que otros. Unos niños del siglo XX escuchan de labios de su maestro la historia de Moisés y reaccionan igual que los contemporáneos del personaje:

Sin embargo, ya había maestros y niños que eran iguales a los que hoy se hallan encerrados en clase. Tenía que haberlos, porque el maestro habla de 
aquellos niños que fueron amigos de Moisés exactamente igual que hablaría de Trompo y de sus compañeros. Exactamente igual [Prieto, 1956: 100].

En Buenas noches, Argüelles esa concepción se ve respaldada por una concepción cíclica del tiempo, de la que uno de los personajes ofrece una curiosa versión infantil. Un hijo pregunta a su padre dónde van a parar los días del pasado, y el padre responde: «Verás, Trompo. Los días forman una cadena que estuviera siempre dando vueltas». Cuando un día está demasiado desgastado, Dios lo retira de la cadena, lo limpia y vuelve a incorporarlo. Así que cada día «nos parece un día distinto», pero en realidad es el mismo que ya alguien ha vivido en otra ocasión [Prieto, 1956: 39]. Como ya vio Mircea Eliade (1982) esa concepción cíclica está muy cerca de una concepción mítica del mundo.

La idea de que solo existe una realidad, la vida, y que la variación está solo en el lenguaje humano, vuelve a aparecer en Encuentro con Ilitia, de 1961: "Si no olvidásemos, no podríamos estar realizando esta repetición con distintos nombres que es la vida» [Prieto, 1961: 51]. En esa misma novela, se introduce una irónica conversación que destaca la irrelevancia de los nombres propios: Ilitia y el narrador se burlan de los viajeros que no paran de preguntar el nombre de las estaciones por las que pasa el tren, ya que para los dos protagonistas la respuesta carece de interés.

El primer ciclo novelístico de Prieto termina con una obra, Prólogo a una muerte, donde uno de los personajes retoma la formulación de las novelas anteriores: «¿No te parece que, en el fondo, todos los hombres somos el mismo hombre colocado en plataformas distintas?» [Prieto, 1965: 76]. Y aunque el propio personaje da una respuesta negativa a la pregunta, es claro que esta expresa, una vez más, la postura del novelista.

Así que ya en las novelas de los años 50 y 60, Prieto formula con claridad, aunque con las naturales variaciones, una visión muy preci- 
sa del mundo. En ella se privilegia el todo sobre los individuos, el fondo compartido de las cosas sobre sus diferencias y, en términos más platónicos, los universales sobre los particulares.

Esa intuición básica, que recorre las primeras novelas de Prieto, acabará formulándose de manera más sistemática y más coherente a través de su teoría de la fusión mítica. El concepto aparece definido por primera vez en Ensayo semiológico de sistemas literarios [1972: 135187]. En la fusión mítica, el escritor (o, más genéricamente, cualquier lector) se desplaza al mundo y al tiempo de otro escritor y se identifica con él [Hernández Esteban, 2005]. Por consiguiente, la fusión mítica es, antes que nada, un esfuerzo de empatía y de participación emocional en las experiencias ajenas, identificadas con las propias. Pero es también algo más. Tomemos, siguiendo a Prieto [1972: 142-151], el ejemplo de Safo y Leopardi. Si el poeta italiano y la poeta griega se identifican es porque ambos encarnan algo así como el arquetipo platónico del enamorado condenado a la infelicidad por sus defectos físicos. Un arquetipo que, como tal, se sitúa al margen del tiempo:

Leopardi al navegar por ella [la voz de Safo] navega por una constante humana atemporal $[\ldots]$. Es una fusión mítica perfecta donde ambos, desde muy lejanos tiempos, realizan al unísono, como una misma persona, ese salto de Léucade [...] [Prieto, 1972: 150-151].

Una constante atemporal no está muy lejos de las ideas platónicas. De hecho, en la fusión «los accidentes temporales se pierden a favor de la atemporalidad del mito». Quedan al descubierto, por tanto, las esencias puras, ajenas a los «accidentes temporales», que son, como afirmaban los escolásticos, principium individuationis.

Desde ese momento, toda la producción del novelista jugará una y otra vez con esa identificación. Por ejemplo, en La plaza de la memoria (1995), el protagonista escucha a un anciano caballero (protagonista, a su vez, de una novela anterior) que cuenta su historia de amor: 
Lo que narraba el caballero era una hermosa historia de amor que transcurrió en América y que mi intimidad reconocía en su experiencia [Prieto, 1995: 43].

He aquí la situación paradigmática de la fusión mítica, en la que el lector (el oyente, en este caso), reconoce como experiencia propia la historia que cuenta el autor. Uno y otro, autor y oyente, son el mismo hombre, porque ambos son solo advocaciones del ser verdadero, nombres distintos que adopta la corriente única de la Vida. De hecho, en la escena que estoy analizando, el protagonista comete por un momento el error de creer que su experiencia amorosa y la del anciano caballero son diferentes, y que diferentes son también sus amadas; pero enseguida rectifica:

Pero el nombre de Coya (la amada del caballero) no se correspondía con la realidad $[\ldots]$.

Se llamaba Carmen [la amada del narrador] - le contradije.

¿Y qué importa un nombre? - me respondió. [...].

Entonces yo me sumé a la narración de la historia: el caballero anciano y yo contábamos la misma historia, alternándonos en la palabra, y no importaba que dijésemos Coya o Carmen. Lo importante era la vida, la misma vida, que recuperaba la palabra [Prieto, 1995: 43].

Cuarenta años después de Tres pisadas de hombre, el novelista vuelve a afirmar que lo importante es la vida, y que decimos «Coya y Carmen» (o «rama, jabé, boa y liana»), pero solo porque introducimos diferencias ficticias donde no las hay.

La plaza de la memoria no es, obviamente, un caso aislado. El ciego de Quíos, de 1996, vuelve a retomar formulaciones de las primeras novelas, aunque ahora en el contexto de la fusión mítica. El protagonista del relato, Homero, se enamora de una muchacha, Euriclea, y el narrador comenta:

Y aun comprendió que aquella Euriclea [...] podría ser en su mirada la mirada de otras mujeres [...] a la que podría prestarle para correr el tiempo la esencia de la vida con el disfraz de otros nombres. [Prieto, 1996: 36]. 
La formulación es muy parecida a la de Encuentro con Iliatia: «esa repetición con distintos nombres y protagonistas que es la vida». Solo que aquí es aún más claro que lo verdaderamente real es el todo indivisible, la vida, y que los nombres, es decir, las variaciones individuales, pertenecen al ámbito de lo ilusorio («con el disfraz de otros nombres»).

Más adelante, Homero conoce a otra muchacha, Eurídice, y la identifica con la primera:

Y encontró el aedo peregrino que la mirada de ella era como la mirada de Euriclea, de tal manera que se confundían en él los nombres de Eurídice y Euriclea en un común sonido [...] [Prieto, 1996: 148].

Ya Luigi había sentido que confundía a dos mujeres: «Y el rostro de María Elena se me confundía con el rostro de ella [Tuhaí, la muchacha indígena]». Solo los personajes que se quedan en el plano superficial creen que la diferencia en el nombre tiene algún relieve. Nausicaa le pregunta a Homero si era hermosa Euriclea:

- ¿Y Euriclea, era hermosa Euriclea?

- Creo- respondió serenamente el aedo-que Euriclea eres tú.

- Mi nombre es Nausicaa- respondió la muchacha [Prieto, 1996: 185].

Al igual que el protagonista de La plaza de la memoria, Nausicaa se opone al aparente error de su interlocutor porque no advierte que no hay tal error, ya que la diferencia de nombre es irrelevante, cuando no engañosa. Los dos personajes se equivocan de la misma manera: «Se llamaba Carmen- le contradije», «Mi nombre es Nausicaa», corrigen, cuando en realidad podrían llamarse perfectamente «Coya»o «Euriclea».

La confusión de los nombres es una de las consecuencias de la superioridad de la vida, o de los arquetipos, sobre sus encarnaciones particulares. La anonimia de los personajes parece obedecer a la misma idea. Muchos de los seres de ficción de Prieto carecen de nombre propio. No lo tiene, por ejemplo, el Profesor de Secretum, ni 
sus antagonistas (el Economista o el Sociólogo); no lo tiene el narrador de El embajador, ni el del Palmaverde, ni el de Carta sin tiempo. Este caso es quizá el de mayor interés, porque Prieto teoriza sobre el sentido de ese anonimato. El novelista finge estar editando una historia narrada por un caballero, que nunca desvela su nombre:

Tanto el nombre del que escribe como el de la dama permanecen ocultos, jamás se denominan, y este es uno de los puntos oscuros de la novela que posiblemente preocupe a algún erudito, pero no a nosotros, porque el valor significativo de esta anonimidad está claro por la defensa de la persona, frente al individuo, que se realiza en estas páginas [Prieto, 1975: 10].

Así que la deliberada ocultación del nombre obedece a una desconfianza ante el individuo, ante todo aquello que tiende a aislar a los particulares frente a lo universal.

Un último caso bastará para mostrar hasta qué punto esa concepción recorre toda la narrativa de Prieto. Ya desde su mismo título Una y todas las guerras se sitúa, como señala Ángel García Galiano en el prólogo a la traducción italiana de El ciego de Quíos, «più in là del tempo lineare del cronos umano» [Prieto, 2020: 8]. De hecho, un mismo personaje, extraordinariamente longevo, interviene en las numerosas guerras y batallas de la obra, desde Troya hasta Stalingrado. Pues en realidad esa multiplicidad de campañas es solo aparente, y es natural que todas tengan el mismo protagonista:

Todos los días, en algún punto de la tierra, estaba instalada la guerra; la misma guerra que cambiaba unos nombres con el fin de mentir su novedad. [Prieto, 2003: 89].

Vale la pena recordar con qué frecuencia aparece el adjetivo mismo, incluso en esta pequeña muestra de ejemplos que he recogido. Gad y el maestro que humilló por primera vez a Juan son el mismo hombre. En Prólogo a una muerte, «todos los hombres somos el mismo hombre». En la reflexión teórica de Ensayo semiológico, Safo y Leopardi «realizan al unísono, como una misma persona, el salto de Léucade». En La plaza 
de memoria, el caballero anciano y el protagonista «contábamos la misma historia porque lo importante es la vida, la misma vida que recuperaba la palabra». Y, en fin, en Una y todas las guerras, todas las guerras, son en realidad, la misma guerra. Coherente con esta premisa, el novelista marca las palabras «diferencia» $\mathrm{y}$ «novedad» con el signo de lo engañoso. En Tres pisadas «únicamente el hombre diferencia a las partículas». En Buenas noches, Argüelles, el día que Dios vuelve a enviar a la tierra «nos parece un día distinto (pero en realidad no lo es)»; en Encuentro con Ilitia, la vida es repetición «con distintos nombres y protagonistas»; en Una y todas las guerras, las múltiples guerras «mienten una novedad».

Así que las novelas de la fusión mítica llevan a sus últimas consecuencias las premisas de las primeras novelas. Unos personajes no son simplemente idénticos a otros, como los niños actuales son iguales a los de la época de Moisés: son, de alguna forma, los mismos. Y los son de manera permanente, no episódica, como Gad y el maestro de Lavapiés. Así que un personaje del presente que se funde con Horacio puede pasearse por la Roma de Augusto, y otro que se identifica con Diego Hurtado de Mendoza puede mantener conversaciones con la amada de este. Pero el punto de partida de estos juegos, desconocidos en Prieto hasta 1972, están ya en su producción juvenil. En ella se formula la idea de que cualquier vida es solo un fragmento de la vida, y de que el tiempo gira en círculo y vuelve una y otra vez sobre sus pasos. O, de manera aún más radical, que la vida es una y está fuera del tiempo.

En términos lingüísticos cabe decir que toda la obra de Prieto obedece a una suerte de nominalismo a la inversa. Para Guillermo de Ockham, la verdadera realidad son los particulares, de forma que los términos generales son solo palabras, soplos de voz, útiles quizás para orientarnos en el mundo, pero no remiten a nada sustancial [Andrés, 1969 y Michon, 1994]. Para Antonio Prieto, la verdad parece ser la contraria: lo verdaderamente importante, cuando no lo verdaderamente real, son las figuras míticas, las constantes atemporales, 
la Vida, la Guerra arquetípica. Así que los nombres propios, que remiten a una multiplicidad, son irrelevantes o engañosos.

Sería preciso contextualizar en un panorama más amplio esas ideas de Prieto. Analizar, por ejemplo, cuáles son sus raíces lejanas o inmediatas y sus paralelos con otros textos. Me he referido a la concepción cíclica del tiempo, lo que sugiere de inmediato el nombre de Nietzsche. Pero podrían aducirse otros, como el de Séneca y los filósofos estoicos, agudamente conscientes de su inserción en el Todo. Mucho más cerca del novelista, hay un poema de Borges extrañamente semejante a Una y todas las guerras, con su protagonista único y su única guerra que se perpetúa con nombres diferentes:

Un solo hombre ha nacido, un solo hombre ha muerto sobre la tierra.

Pensar lo contrario es mera estadística, una adición imposible.

No menos imposible que sumar el olor de la lluvia o el sueño que anteanoche soñaste.

[...]

Un solo hombre ha muerto en Ilión, en el Metauro, en Hastings, en Austerlitz, en Trafalgar, en Gettysburg. [Borges, 1972: 100]

El propio Borges apunta a la raíz última de esa concepción de la realidad cuando comenta un famoso pasaje de Coleridge:

Observa Coleridge que todos los hombres nacen aristotélicos o platónicos; los últimos sienten que las clases, los órdenes y los géneros son realidades; los primeros, que son generalizaciones [...] [Borges, 1976: 118].

Si nos atenemos a esa dicotomía, la obra novelística de Antonio Prieto es, ya desde sus comienzos, la de un hombre que ha nacido inequívocamente platónico. 


\section{BIBLIOGRAFÍA}

ANDRÉS, Teodoro de (1969): El nominalismo de Guillermo de Ockham como filosofía del lenguaje, Madrid, Gredos.

BORGES, Jorge Luis (1976): Otras inquisiciones, Madrid, Alianza. (1972): Obra poética, Madrid, Alianza.

ELIADE, Mircea (1982): El mito del eterno retorno: arquetipos y repetición, Madrid, Alianza.

HERNÁNDEZ, María (2005): «El mundo mítico en la narrativa de Antonio Prieto», en Antonio Prieto en su texto total, ed. Gaspar Garrote Bernal (Málaga, Universidad de Málaga) I, 63-110.

Michon, Cyrille (1994): Nominalisme. La théorie de la signification d'Occam, París, Vrin.

Prieto, Antonio (2020): Il cieco di Chio, trad. Piero Salerno, pról. Ángel García Galiano, Palermo, Unipapress.

(2003): Una y todas las guerras, Barcelona, Seix Barral.

(1996): El ciego de Quíos, Barcelona, Seix Barral.

(1995): La plaza de la memoria, Sevilla, Guadalquivir.

(1983): Tres pisadas de hombre, Barcelona, Planeta.

(1975): Carta sin tiempo, Madrid, Magisterio Español.

(1972): Ensayo semiológico de sistemas literarios, Barcelona, Planeta.

(1965): Prólogo a una muerte, Barcelona, Planeta.

(1961): Encuentro con Ilitia, Barcelona, Planeta.

(1956): Buenas noches, Argïelles, Barcelona, Planeta. 